\title{
Concepts of a Performance-based Building Regulatory System for the United States
}

\author{
BRIAN J. MEACHAM \\ Society of Fire Protection Engineers \\ One Liberty Square \\ Boston, MA 02109 USA
}

\begin{abstract}
There is much discussion in the United States regarding the transition to the use of performance-based codes and fire safety design methods. To provide a common forum for discussion on this transition, the Society of Fire Protection Engineers convened a focus group of representatives from the United States' fire and building communities to discuss concepts and components of a performance-based regulatory system. A conceptual model, terminology and definitions were distributed to the group as a basis for discussion. Participants were asked to provide comments. Preliminary response to the conceptual model, terminology and definitions was positive. All comments received were compiled and distributed to all participants, and a two-day meeting was convened on 25-26 April 1996 to facilitate discussion and gain consensus on the future direction for the United States. This paper will present the conceptual model and the focus group consensus on the direction for a performance-based regulatory system in the United States.
\end{abstract}

KEY WORDS: Performance-based regulatory system, performance-based codes, performance-based fire safety design, building fire safety

\section{INTRODUCTION}

Various sectors of the United States' building and fire communities have recently begun to transition their predominantly prescriptive-based building and fire regulations to ones incorporating more performance-based language. The commitment to such a transition first became evident with the publication of the National Fire Protection Association (NFPA) report 'NFPA's Future in Performance-Based Codes and Standards" in 1995.' Since then, 
the International Code Council (ICC) ${ }^{*}$ and other codes- and standards-making organizations in the United States have actively begun a transition to the use of performance-based concepts as well.

However, this transition has not been without growing pains. Given the current lack of a single building code in the United States, and the fact that the building regulations are not promulgated by the Federal Government on a national basis (as in most other countries), there are concerns that a non-unified approach to a performance-based regulatory system will result in confusion, in a lack of confidence, and ultimately, in the failure of such a system.

To address these concerns, the Society of Fire Protection Engineers (SFPE), under a grant from the National Institute for Standards and Technology (NIST), convened a focus group of representatives from the building and fire communities to discuss concepts, terminology, and definitions for a performance-based system for the United States. The purpose of the focus group is two-fold: to gain insight into the role the participants play in the development, implementation, and use of performance-based building and fire codes and standards, and to gain consensus on the fundamental features and components of a performance-based system for the United States.

To initiate discussion amongst the focus group participants, the SFPE prepared and disseminated the document "Concepts of a Performance-Based System for the United States." The focus group participants were asked to comment on the document. The comments were distributed to each of the focus group participants. A two-day meeting was then held on 25-26 April 1996, in Arlington, VA, to discuss the concepts outlined in the paper, identify concerns, and come to consensus on the direction of a performance-based system for the United States.

A summary of the SFPE document and the focus group consensus is presented.

\section{CONCEPTS OF A PERFORMANCE-BASED SYSTEM}

The SFPE document "Concepts of a Performance-Based System for the United States" proposed a three-component model for a performance-based system: The Code, Standards and Practices, and Evaluation and Design Tools. The document also included a list of terminology and definitions, and a discussion of the role of fire protection engineers in the system. (For the purposes of this summary, terminology, definitions, and the role of fire protection engineers have been omitted.) This SFPE document was based in part on the current regulatory structure in the United States, using structural provisions as a guide, and in part on key features of the regulatory structures of countries which have a performance-based regulatory system in planning or in place. (These countries included Australia, New Zealand and the United Kingdom. An overview of international efforts is available from the SFPE. ${ }^{3}$ )

\footnotetext{
* The International Code Council is an umbrella organization of the three model building code organizations in the United States [the Building Officials and Code Administrators International, Inc. (BOCA), the International Conference of Building Officials (ICBO), and the Southern Building Code Congress International (SBCCI)], whose mission is to develop national building, fire, mechanical and plumbing codes for the United States.
} 


\section{Basic Components and Structure of a Performance-Based System}

The current building regulatory system in the United States is predominantly prescriptive(specification-) based, and consists of a collection of codes and standards that describe how buildings should be designed, built, protected and maintained with regard to the health, safety and amenity of the general public. For the most part, this is accomplished using documents that specify both what is required for health, safety and amenity, and how these requirements are to be met.

Although the approach of specifying both what is required by the code and how the requirements are to be met may be appropriate for a prescriptive-based system, it may not be appropriate for a performance-based system (where the how may be met in a number of ways). As an alternative approach, a performance-based system based on three primary components was suggested. The three components are:

1. The Code, which through societal goals, functional objectives and performance requirements reflects society's expectations of the level of health and safety provided in buildings (e.g., items such as acceptable access, egress, ventilation, fire protection, electrical services, sanitary services, etc.);

2. Standards and Practices, which are separate documents, adopted by reference, that describe accepted methods for complying with the requirements of the code(s); and,

3. Evaluation and Design Tools, which provide accepted methods for assisting in the development, review and verification of designs in accordance with engineering standards and practices.

Such a model, if adopted, would provide a clear differentiation between:

1. The requirements of the code (the what),

2. The acceptable means for complying with the requirements of the code (the how), and

3. The acceptable means for demonstrating that the proposed solutions comply with the requirements of the code.

At a minimum, the code should explicitly state societal goals, functional objectives and performance requirements. Standards and practices would then provide acceptable methods for meeting the requirements of the code. Although these may be included in the code, they may be more appropriately referenced by the code. Acceptable methods will likely include both prescribed solutions (e.g., deemed-to-satisfy) and engineering standards, practices, tools and methodologies that can be used in an accepted manner for both design and verification of compliance (a performance-based option).

\section{The Code: Prescriptive-Based Codes vs. Performance-Based Codes}

Prescriptive-based codes describe the desired level of performance for health and safety through a set of minimum requirements that are generic by occupancy. Examples include occupancy-based spacing requirements for detectors or sprinklers, a specified fire resistance rating for an interior wall, or the maximum travel distance to an exit. While these may be 
appropriate for a general minimum, the true objective of a stated requirement in a specific design situation can be lost.

For example, one may know the maximum permitted travel distance to the exterior of the building, but not know the extent of smoke spread within a building before the last occupant is expected to have escaped. Thus, if the intended objective of the travel distance restriction is life safety, it would be easy to state that the requirement has been met, but difficult to state that the objective has been met.

By contrast, performance-based codes describe requirements for health and safety through a set of flexibly defined performance objectives and functional requirements. Examples include broad statements such as:

- the objective of this requirement is to safeguard people from injury from the effects of fire while evacuating a building, and,

- installation of an automatic suppression system intended to control the development and spread of fire shall be appropriate to the building use and characteristics, the fire hazard, the height of the building and the size of the fire compartment.

In these cases, the solution is not prescribed in the regulations. Rather, it is the responsibility of the designer to demonstrate that the proposed design meets the health and safety needs of the community by meeting the functional objectives and performance requirements of the code. This demonstration of compliance can be accomplished through the application of accepted methods, which are either deemed-to-satisfy (specified) solutions or performancebased design solutions. Performance-based design solutions utilize engineering standards, practices, tools and methodologies.

\section{Standards and Practices}

For the purposes of this model, a standard is considered a consensus document that provides a set of rules, conditions, or requirements concerned with: definition of terms; classification of components; delineation of procedures; specification of dimensions, materials, performance, design or operations; description of fit or measurement of size; or measurement of quality and quantity in describing materials, products, systems, services or practices. Standards may be written in mandatory or non-mandatory language.

An engineering standard, for example, could be defined as a standard written in mandatory language that relates specifically to an engineering analysis or design process or procedure. Prior to becoming a standard, such an engineering document could be used as an engineering practice (i.e., a pre-standardization document, developed within and accepted by a recognized engineering discipline, that relates specifically to an engineering analysis or design process or procedure related to the expertise of that discipline). An example of an engineering practice might be an engineering practice for the calculation of structural fire resistance. One might expect such a document to identify accepted methods for analysis and design, and include 
specific reference to material properties, dimensions and orientation, failure temperatures, effects of protective coverings, and other pertinent information.

A performance-based system requires standards of all types, including engineering analysis and design, and component and system installation and maintenance. These will exist in both performance-based format and prescriptive- (specification-) based format. For example, one accepted method for the design of automatic fire detectors may be NFPA 72, The National Fire Alarm Code ${ }^{\circledR}$ and another might be an engineering practice for performance-based design of fire detection systems that has been developed and accepted within the fire protection engineering community.

Similarly, a document is needed that outlines an overall approach to performance-based fire safety design for buildings. This could be an engineering standard or an engineering practice (other countries use the terms engineering guide and code of practice for such documents). Having such a document is essential: although a performance-based fire safety design can be undertaken outside of a performance-based system (i.e., where no performance-based code is in place), a performance-based system must have at least one generally accepted performance-based design approach (engineering practice) to outline the process and procedure for complying with the code. In the context of a performance-based system, a performance-based design approach will provide a means to demonstrate that the health and safety requirements of a performance-based code are met by providing a process to evaluate design options against the performance objectives and functional statements using accepted methods.

\section{Evaluation and Design Tools}

Evaluation and design tools are accepted methods for assisting in the development, review and verification of designs in accordance with engineering standards and practices. Fire protection engineering tools and methodologies encompass those equations, correlations, models and procedures used for engineering analysis and prediction of fire and fire related phenomena. Computer models used in fire and life safety analysis and design, for example, are considered fire protection engineering tools. So too are many of the equations and correlations found in the SFPE Handbook of Fire Protection Engineering. ${ }^{4}$

The difference between an engineering practice and an evaluation and design tool is that an engineering practice provides the process and procedure to solve a global problem, and an evaluation and design tool is used to solve or verify components of the global problem in accordance with an engineering practice.

For example, to estimate the available time for safe egress from a building, one might well determine building characteristics and features, fuel loading and arrangement (contents, interior finish, etc.), determine occupant characteristics, develop performance criteria (e.g., what renders the egress path unsafe), develop potential fire scenarios, evaluate protection alternatives and evaluate evacuation factors. A process such as this would be well-suited to an engineering practice for evaluation of safe egress time. 
Within this process, it will be necessary to perform a number of specific analyses, such as estimation of fire growth and spread, estimation of smoke production and propagation and estimation of fire detector activation. For these analyses, specific tools, such as computer fire models, and methodologies, such as those outlined in the SFPE Handbook for estimation of fire detector response to a growing fire, may be applied.

\section{FOCUS GROUP DISCUSSION AND CONSENSUS}

The first meeting of the SFPE Focus Group on Concepts of a Performance-Based System for the United States convened on 25-26 April 1996 at the Doubletree Hotel in Arlington, VA. The goal was to bring together a wide cross-section of the United States' building and fire communities to discuss the transition towards the use of performance-based codes, standards and fire safety engineering and design methods in the United States.

\section{The Participants}

The goal of assembling a wide cross-section of the United States' building and fire communities was achieved, and representatives included:

- Building Officials

- Building Owners and Managers

- Codes- and Standards-Making Organizations

- Design Professionals

- Fire Officials

- Government Agencies

- Insurance Companies

- Research Organizations

- Test Laboratories

- Universities

In addition, representatives from various international organizations, actively involved in the development, application or enforcement of performance-based regulations or fire safety design methods in their countries, participated as well:

- Arup Fire, UK

- Australian Building Codes Board, Australia

- Building Industry Authority, New Zealand

- Department of the Environment, UK

- Fire Code Reform Centre Limited, Australia

- Glasgow Caledonia University, Scotland

- Loss Prevention Council, England

- International Council on Building Research Studies and Documentation, The Netherlands

- National Research Council, Canada

- VTT Fire Technology, Finland 


\section{Group Discussion and Consensus}

The following summarizes the consensus of the focus group on those issues discussed. ${ }^{5}$ Bulleted text reflects the consensus as developed at the meeting, with additional commentary added to provide clarification. No significance should be placed on the order in which the bullets appear.

Topic 1: Why does there appear to be such a strong movement towards performance-based codes in the United States?

This discussion was intended to capture the essence of why the participants felt that the United States is moving towards the inclusion of performance-based codes, standards and fire safety design methods in its building regulatory system. These comments reflect the general feeling of the group as to what seem to be the motivating factors, what the resulting system might look like, and what remains to be done. Consensus on specific issues follows under subsequent headings.

\section{Why are "we" doing this? What will be achieved?}

- To provide a better framework for communication between the policy makers, the people who purchase fire protection (services, systems and materials), and the people who deliver fire protection (services, systems and materials).

- To provide better definition of what is being delivered for the cost. There is a perception of undue redundancy and cost in the present system, and a performance-based system is expected to provide improved value by providing clear explanation of fire and life safety objectives and by minimizing redundancy. Such a system would also encourage cost/benefit analyses and decision making for building design and construction.

- To encourage the development of tools and techniques to evaluate building performance and to evaluate prescriptive requirements. Not only will the $5-15 \%$ of buildings expected to be designed using performance-based concepts benefit, but the remaining 85 $95 \%$ will benefit as well

- To help identify and target sectors of the built environment where the risks are higher.

- To help identify and target sectors that deter growth and innovation in services, systems $\&$ materials.

- To foster the development and use of new and innovative materials.

- To maintain global competitiveness and respond to global market forces. As global corporations look to locate, the regulatory environment will be an important factor. Also, the United States needs to be competitive in the global design and construction markets.

- To gain recognition of fire protection engineering as a true engineering discipline (in the same way as civil or mechanical engineering, for example), and to achieve better fire protection engineering.

How do we get there?

- Expand concept of using equivalency by introducing objective statements first, then transition to a "total" performance-based system over time.

- Do not throw away what works: make it better and allow a performance-based option. 
- Provide an "integrated" system that retains the prescriptive and includes performance.

What do we have to do, have, develop and consider?

- Examples of economic benefit would be useful to have.

- The development of an analytical tool to demonstrate the economic benefit would be useful.

- The development of tools and techniques to evaluate performance and to evaluate prescriptive requirements are needed.

- There needs to be a linkage between those objectives extracted from our current prescriptive requirements and those that may be developed independently under a performance-based structure (i.e., the "bottom-up" objectives and the "top-down" objectives). If this is not done, there may be incompatibilities.

\section{Topic 2: Basic Components and Structure of a Performance-Based System}

This issue focused on the conceptual model for a performance-based regulatory system discussed earlier. Items that were considered under this topic included: Is a performancebased system needed? Does the SFPE "model" achieve the intent of such a system? If not, what is missing? Should societal goals, functional objectives, performance requirements and accepted methods be specified in a single document or reside in separate documents? The following constitutes the consensus reached by the entire focus group on this topic.

- A performance-based system needs to be pursued. (As discussed in the Topic 1 session, this would be an integrated system, maintaining what we have, and introducing the performance-based concepts listed below.)

- Such a system would include goals, objectives, requirements and methods. (These terms are based on the concepts of goals, functional objectives, performance requirements and accepted methods outlined in the SFPE document. ${ }^{2}$ )

- The term societal goal should be replaced with the term policy goal.

- The system will have a variety of goals and objectives.

- To start, objectives need to be extracted from the existing prescriptive codes and quantified. Quantification of objectives is critical for evaluation/verification purposes.

- Accepted methods need to include both an engineering guide, for undertaking performance-based solutions, and a set of accepted/deemed-to-satisfy solutions, likely to be the currently accepted prescriptive requirements.

- A "road map" for implementation of the system needs to be developed. regulatory/regulator's tool for transition and implementing.)

- A "users guide" for the system needs to be developed. (For general use: now that we have this system, how do we use it?)

- Further work is needed on the definitions. (As proposed in the SFPE document. ${ }^{2}$ )

\section{Topic 3: Prescriptive Codes and Performance-Based Codes}

This topic focused on the differences between prescriptive codes and performance-based codes. Items that the group considered included: Do the current codes clearly identify measurable goals and objectives? If not, how should they be developed, and by whom? Who 
determines the required performance (to meet the objectives)? The following constitutes the consensus reached by the entire focus group on this topic.

- Current prescriptive codes seldom have explicit fire and life safety goals and objectives.

- Goals and objectives need to be developed by all affected interests.

- Performance requirements need to be developed by consensus of those experienced individuals (professionals, organizations) who are qualified to translate verifiable goals and objectives into quantified terms.

Although consensus could not be reached on how to identify "who is qualified," there was clear consensus that the determination of performance requirements had to be done by those who have the expertise to translate the goals and objectives into quantified terms. Discussion indicated that this should be psychologists for human behavior, medical doctors for tenability or survivability criteria, fire scientists and engineers for fire related criteria, and the like.

\section{Topic 4: Engineering Standards and Practice Documents (Methods)}

This topic focused primarily on engineering standards and practice documents (methods) that would be used for describing a process to be followed in achieving a solution. These are the analysis and design guidance documents (the "how is it done" documents), and do not include the evaluation and design tools (e.g., models) that are used within the analysis or design process. Items that the group considered included: Who develops engineering standards and practices? Who evaluates them on their ability to perform their intended function (who "validates" them)? How are they included in the system such that they can become readily used? The following constitutes the consensus reached by the entire focus group on this topic.

- Engineering standards and practices (methods) need to be developed by and gain a broad professional consensus of the scientific and engineering community. In essence, the scientific and engineering community not only must develop the methods, but must agree to their validity before they can become widely accepted.

- Acceptance of engineering standards and practices within the regulatory system can be gained in one of two ways:

(1) By having a critical peer review within the scientific and engineering community and a "reality check" by a broader community (such as might be gained through a broader consensus process similar to the NFPA process.)

This discussion included the commentary that the scientific and engineering communities have the expertise necessary to develop engineering methods, but that they should not "operate in a vacuum" and develop methods that cannot be readily used or understood by the broader building and fire communities.

(2) When an engineering method has not received critical peer review by the engineering and scientific communities, nor a "reality check" by the broader community, the burden of demonstrating the "acceptability" of the method is on the 
proposer of the method. Criteria for demonstrating the acceptability of an engineering method is to be provided in the code.

The discussion around this option focused on the need to allow engineers the flexibility to engineer solutions for which guidance documents may not exist, and on cases where the engineer wants to use an alternative approach that has not yet been peer reviewed. This option will only be truly effective, however, if there are acceptability criteria/factors in the code to assist enforcement officials in the review of such a method.

In essence, the group agreed that the engineering community must be the driving force behind development and "validation" of engineering methodologies. Traditionally, this is done through a peer-review process and subsequent acceptance and use in the wider community. An example might be a code reference (wide community acceptance) to an acceptable method for calculating the deflection of a reinforced concrete structural member (peer review and consensus of the scientific and engineering community). However, if such a reference is not included in the code, there needs to be a means to determine the acceptability of a proposed engineering approach. This can be accomplished by including basic criteria/requirements in the code (e.g., wording to the effect that "....alternative methods for meeting these objectives must consider the following...”).

\section{Topic 5: Evaluation (Verification) and Design Tools}

This topic focused primarily on the evaluation and design tools that would be used within an engineering standard or practice document (method). These include such items as models, computer models, empirical equations, correlations, test methods and data. Items that the group considered included: Who develops these evaluation and design tools? Who deems them to be acceptable? Who "validates" them? Who can/should be expected to properly utilize these tools? How do we fill needed gaps? The following constitutes the consensus reached by the entire focus group on this topic.

- Evaluation and design tools are to be developed by those with the expertise, e.g., the profession, academia and research organizations.

- Validation means different things to different people. For this reason, perhaps the term should not be used. The critical factor is confidence.

The term valid (validated, or validity) has a range of meanings as related to engineering evaluation and design tools. These include the validity of the fundamental equations (correlations, assumptions, etc.), the validity of the software (in the case of a computer model), and the validity of the modeled relationship to reality (does the modeled outcome accurately reflect what happens in "real life"). In each of these cases, the real issues are certainty and confidence. In other words, how certain is one of the fundamental equations, the software, and the predictive capability? Or, when stated in a more scientific manner, has one identified, quantified, and addressed the uncertainties in the evaluation or design tool? For many of the complex tools currently used, specifically computer fire models, it is not clear that the uncertainties have been identified, quantified, 
or addressed. As a result, both the users of the models and those who review model applications often lack confidence in the models' results. As a means to increase confidence in the models, the issue of uncertainty needs to be addressed. In addition, education and communication will play a vital role in the acceptance of any tool as being "valid" for its intended use. The more one understands about an engineering tool (e.g., use and limitations), the more confident one can feel about its use.

- Acceptance of evaluation and design tools is a process that includes acceptance by the profession (critical peer review and professional acceptance), acceptance by the users (of the tool's use, application and limitations), and ultimately, acceptance by the marketplace.

As with the above discussion on validation, the real issue with acceptance is one of confidence in the tool and in the user of the tool.

- Before we (the professional community and the broader community) can identify where all the gaps are, we need to know what we have. As the first step, it would be extremely useful to compile a complete inventory of all of the tools (in this case, primarily computer-based tools) that are currently available for evaluation and design. Such a list should include all pertinent tools, including fire science, engineering (of all types), medical, physiological, psychological, toxicological, etc.

The intent here would be to compile a complete list of what is available, and perhaps, provide some indication of use, application and limitations of each. It was suggested that this endeavor might be an appropriate role for the SFPE. Exactly what information would be included about the tools in such an inventory was not discussed.

- One existing gap is the lack of data, specifically for the models.

Although there was no consensus on what we should do, it was clear that the shortage of "valid" data is a critical factor in the "confidence" issue. It was suggested that this problem is bigger than any one group or organization, and that national or international policy/initiatives may be necessary to adequately address this shortcoming.

\section{SUMMARY}

A conceptual model for a performance-based regulatory system for the United States was proposed and discussed. Consensus was reached on a number of items, including the need to pursue a performance-based building regulatory system for the United States. Such a system would likely spawn from the present system, would include explicit policy level goals, functional objectives and performance requirements in the codes (to describe the level of safety that is desired), and would utilize both prescriptive solutions (as we currently have) and performance-based solutions as acceptable means to provide the desired level of safety. 
It was suggested that the first steps along this path will likely include:

- Extraction and quantification of goals and objectives from the current codes (primarily by the codes- and standards-making organizations),

- Development of policy level goals (by all interested parties),

- Development of tools and techniques to measure performance (the responsibility of many professionals, including the SFPE),

- Development of an engineering guide for developing performance-based solutions (a task the SFPE has initiated),

- Development of a common vocabulary and acceptable definitions, and

- Increased education for everyone in the building and fire community.

It was also clear that the United States has a long way to go and change will not occur overnight. Issues such as "qualifications" have yet to be addressed, and consensus has yet to be reached on many of the items discussed in the first meeting. It is anticipated that the focus group will continue to address remaining issues in the coming years.

\section{ACKNOWLEDGMENTS}

The SFPE would like to thank the National Institute for Standards and Technology for their support of the focus group on performance-based codes and fire safety design methods, and associated research, under grant number 60NANB5DO138: Assessment of the Technological Requirements for the Realization of Performance-Based Fire Safety Design in the United States.

\section{REFERENCES}

1 "NFPA's Future in Performance-Based Codes and Standards: Report of the NFPA InHouse Task Group," NFPA, Quincy, MA, July 1995.

${ }^{2}$ Meacham, B.J., "Concepts of a Performance-Based System for the United States," prepared for the SFPE Focus Group on Concepts of a Performance-Based System for the United States, SFPE, Boston, MA, February 1996.

3 Meacham, B.J., "The Evolution of Performance-Based Codes \& Fire Safety Design Methods," SFPE, Boston, MA, USA, 1996, 87 pages.

${ }^{4}$ SFPE Handbook of Fire Protection Engineering, 2nd edition, SFPE and NFPA, Quincy, MA, 1995.

${ }^{5}$ Meacham, B. J., "SFPE Focus Group on Concepts of a Performance-Based System for the United States: Summary of Consensus, Focus Group Meeting, 25-26 April 1996," SFPE, Boston, MA, 9 May 1996. 